\title{
Morphometric Analysis of Distal Epiphysis of Humerus in Northeast Brazil
}

\author{
Nayana Maria Medeiros Vilar Barbosa, ${ }^{1}$ Maria Luísa Freitas de Lucena, ${ }^{1}$ Tássia Santos de Melo, ${ }^{1}$ Amanda do Nascimento \\ Oliveira Carneiro, ${ }^{1}$ Gustavo Henrique Cabral de Paula, ${ }^{1}$ João Pedro Maia Medeiros, ${ }^{1}$ Luana Maria Moura Ferreira, ${ }^{2}$ Alexandre \\ Soares de Mesquita, ${ }^{2}$ Jalles Dantas de Lucena, ${ }^{3}$ André de Sá Braga Oliveira ${ }^{1}$
}

${ }^{1}$ Federal University of Paraiba - UFPB. João Pessoa - PB, João Pessoa, PB, Brazil

${ }^{2}$ Federal University of Ceara - UFC. Fortaleza, CE, Brazil

${ }^{3}$ Faculty Santa Maria - FSM. Cajazeiras, PB, Brazil

Disclose and conflicts of interest: none to be declared by all authors

\begin{abstract}
Introduction: distal epiphysis of the humerus is mainly represented by the condyle of the humerus. It contains a variety of bone structures that are responsible for receiving the radius and ulna forming the elbow joint. Different morphological patterns according to the region studied, nutrition and ethnicity of the populations are described in the literature. Then, thecurrent study aims to analyze the morphometry and morphology of the distal epiphysis of humerus in a population in Northeast Brazil.

Material and Methods: a total of 135 adult humeri were analyzed in this study. Olecranon fossa was classified in two types (triangular or oval) and linear measurements were collected bilaterally using a digital caliper. Values of $p \leq 0.05$ were considered significant.

Results: the present study revealed a predominance of the triangular shape of the olecranon fossa (51.8\%). No differences between sides were found for the morphometric parameters analyzed $(p>0.05)$.

Conclusion: for the first time, an analysis of the morphometric parameters of the distal humerus epiphysis and the main bone structures that compose the elbow joint in the Northeast region of Brazil was carried out. The knowledge of the morphological patterns of the distal epiphysis in this specific population might improve the work of several health professionals such as orthopedists, physiotherapists and radiologists. Diagnosis and treatment could have a better planning with this data, improving, for example, the creation of prostheses in articular fractures of the elbow joint.
\end{abstract}

Keywords: Anatomy, Brazil, Humerus, Osteology.

\section{Introduction}

The distal epiphysis of the humerus is mainly represented by the condyle of the humerus. It is an anatomical region that brings together: the olecranon fossa, the trochlea, the chapter and the coronary and radial fossa. In addition, medial and lateral epicondylesare located in this region. ${ }^{1}$

The distal part of humerus is responsible for receiving the radius and ulna forming the elbow joint. The elbow joint allows mobility and formation of movement angles, which differs between men and women. ${ }^{2}$ Traumas in this region result in serious limitation of movement. So, knowledge of its morphological pattern has a fundamental importance, especially if trauma is in childhood, due to the bone modeling. In addition, surgical methods in individuals who have had considerable bone degeneration, like the elderly, are best planned with a good comprehension of this anatomical region..$^{3-5}$

Anatomical variations of the distal part of humerus are widely documented in the literature. In the olecranon fossa, two variations weredescribed in relation to its shape: triangular and oval. ${ }^{6}$ These shapes are commonly related to their genders. The triangular shape is predominantly found in males, and the oval one in females. ${ }^{6-9}$

Several researchers have turned their attention to the study of the distal epiphysis of the humerus and, in particular, the olecranon fossa, as archaeologists and forensics. ${ }^{5,10}$ Studies show different patterns according to the region studied, nutrition and ethnicity of the populations. ${ }^{8,11}$ Given the importance of scientific investigation and clinical applications of the anatomical study of the distal humeral epiphysis, the present study aimed to analyze the morphology and morphometry of the distal epiphysis in humans from a population in the Northeast of Brazil.

\section{Materials and Methods}

A total of 135 adult human humerus from Northeastern Brazil were analyzed qualitatively and quantitatively, 67 of the right side and 68 of the left side, belonging to the Federal University of Ceará (UFC) and Federal University of Paraíba (UFPB). Humeri 
with important degradation in their distal epiphisys were excluded from the study, once they made their specific analysis impossible. Children's humeri were also excluded from the sample.

First, the olecranon fossa was qualitatively classified as triangular (A) or oval (B) according to the visual conformation suggested by Rogers ${ }^{6}$ (Figure 1).

Then, quantitatively, the following linear measurements were collected: height of the olecranon fossa (XY); width (ZW); distance between the proximal border of the olecranon fossa and the trochlea $(\mathrm{AB})$; distance between medial and lateral epicondyle (BC); distance between the distal border of the olecranon fossa and the trochlea (CD) (Figure 2).
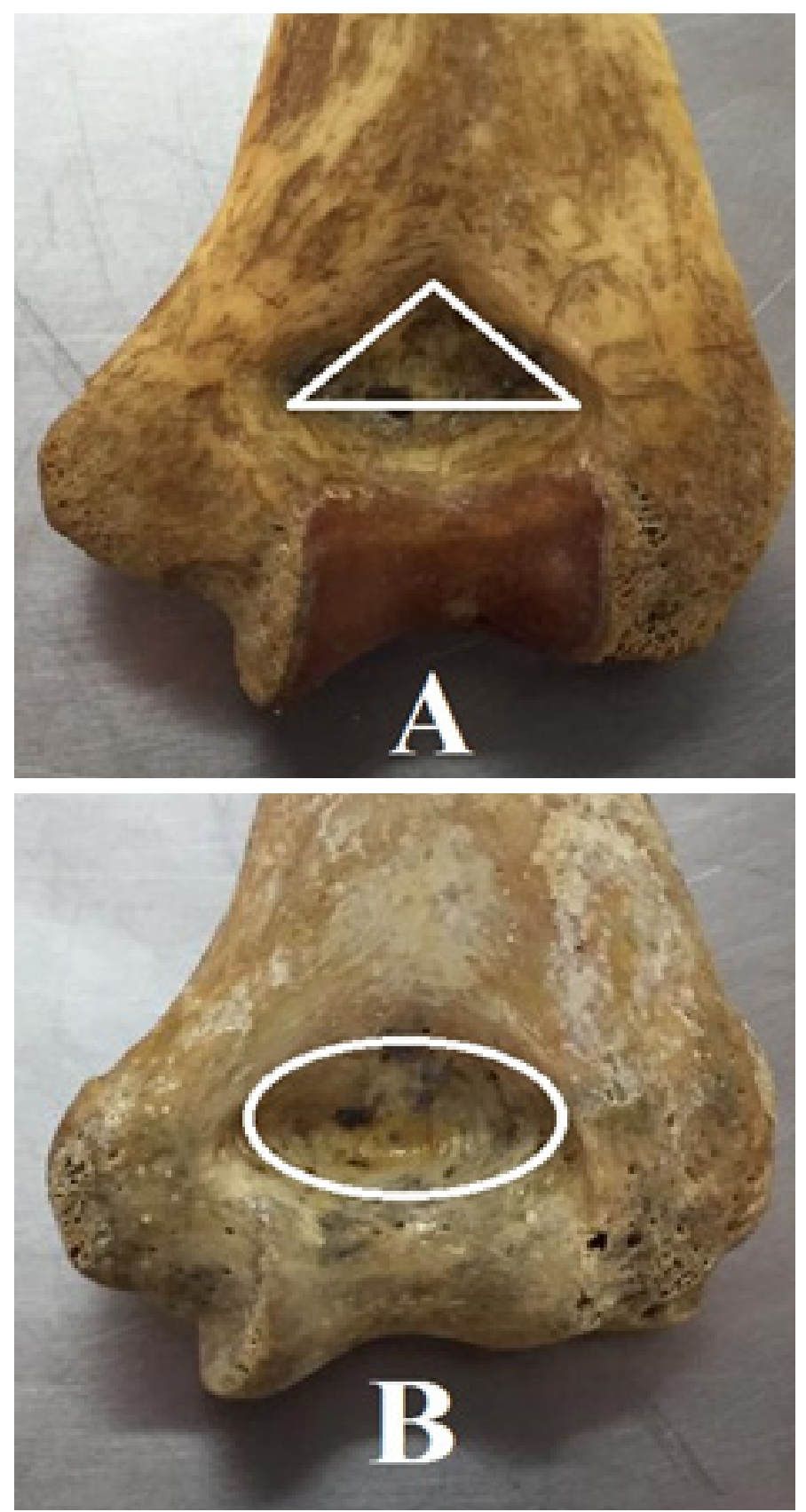

Figure 1. Qualitative analysis of the olecranon fossa by Rogers6: (A) Triangular (B) Oval.

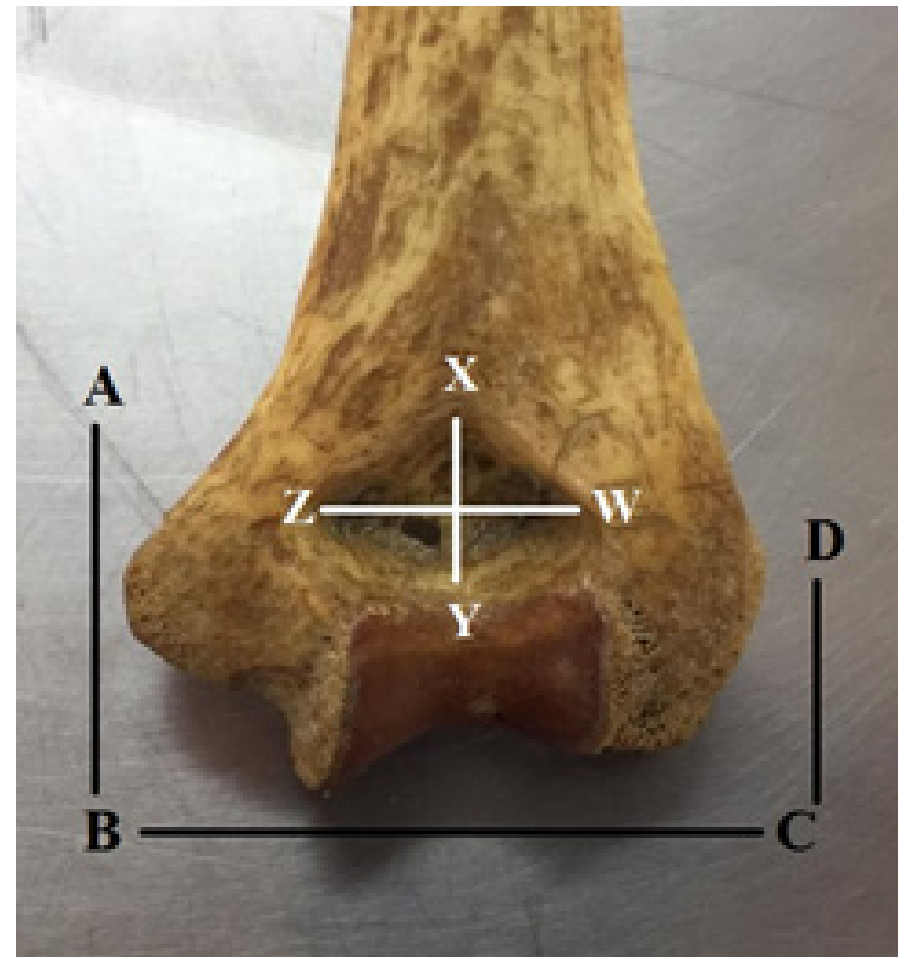

Figure 2. Representation of the morphometric data analyzed from the distal humerus epiphysis. X-Y: Height of the olecranon fossa; Z-W: width of the olecranon fossa; $A-B$ : distance between proximal edge of the fossa and trochlea; $\mathrm{B}-\mathrm{C}$ : distance between medial and lateral epicondyle; C-D: distance between the distal edge of the fossa and the trochlea.

All measurements were made using a $150 \mathrm{~mm}$ digital caliper (Eccofer ${ }^{\circledR}$, João Pessoa, Paraíba, Brazil). Student's t-test was applied to evaluate differences between antimers using GraphPad Prism version 6.00 for Windows, GraphPad Software, USA. Values of $\mathrm{p} \leq 0.05$ were considered significant.

\section{Results}

A total of 135 dry adult humeri were used in this study. Seventy (51.8\%) humeri were described as triangular type (A) according to the Rogers classification ${ }^{6}$ (36 of the right side and 34 of the left side), and 65 (48.1\%) were described as oval type (B) (30 of the right side and 35 of the left side) (Table 1).

The average height of the olecranon fossa (XY) was $18.10 \pm 0.27 \mathrm{~mm}$ on the right side, $18.65 \pm 0.24 \mathrm{~mm}$ on the left side and the average of both was $18.39 \pm 0.18$ $\mathrm{mm}$. The average width of the olecranon fossa (ZW) was $24.24 \pm 0.28 \mathrm{~mm}$ on the right side, $24.73 \pm 0.30 \mathrm{~mm}$ on the left side and the average of both was $24.50 \pm 0.21$ $\mathrm{mm}$ (Table 2).

Table 1. Distribution of the Olecranon fossa types in the analyzed humerus $(\mathrm{N}=135)$.

\begin{tabular}{c|c|c|c}
\hline $\begin{array}{c}\text { Types of Olecranon } \\
\text { Trench }\end{array}$ & Right side & Left side & Total \\
\hline A & $36(51.4 \%)$ & $34(48.6 \%)$ & $70(51.8 \%)$ \\
\hline B & $30(46.1 \%)$ & $35(53.8 \%)$ & $65(48.1 \%)$ \\
\hline
\end{tabular}


Table 2. Mean values \pm standard error, in millimeters $(\mathrm{mm})$, obtained from the morphometric analysis of the five measurements made on the right and left side of distal epiphysis of humerus.

\begin{tabular}{c|c|c|c|c|c|c}
\hline & \multicolumn{2}{|c|}{ Right side } & \multicolumn{2}{c|}{ Left side } & \multicolumn{2}{c}{ Total } \\
\hline Parameters & Min- Max & Mean (SE) & Min- Max & Mean (SE) & Average & p-value \\
\hline XY & $12.30-28.00$ & $18.10(0.27)$ & $13.30-26.60$ & $18.65(0.24)$ & $18.39(0.18)$ & 0.12 \\
\hline ZW & $16.89-33.30$ & $24.24(0.28)$ & $18.00-31.70$ & $24.73(0.30)$ & $24.50(0.21)$ & 0.23 \\
\hline AB & $22.10-40.20$ & $32.95(0.31)$ & $27.20-38.60$ & $32.94(0.27)$ & $32.95(0.20)$ & 0.98 \\
\hline BC & $50.20-66.80$ & $59.76(0.39)$ & $47.80-68.60$ & $59.09(0.42)$ & $59.40(0.29)$ & 0.24 \\
\hline CD & $11.40-28.70$ & $17.02(0.24)$ & $11.80-23.20$ & $16.81(0.22)$ & $16.90(0.16)$ & 0.67 \\
\hline
\end{tabular}

XY: Height of the olecranon fossa; ZW: Width of the olecranon fossa; AB: Distance between proximal edge of the olecranon fossa and the trochlea; BC: Distance between medial and lateral epicondyle; CD: Distance between the distal edge of the olecranon fossa and the trochlea; SE: Standard Error.

The average distance between the proximal edge of the olecranon fossa and the trochlea (AB) was $32.95 \pm$ $0.31 \mathrm{~mm}$ on the right side, $32.94 \pm 0.27 \mathrm{~mm}$ on the left side and the average of both was $32.95 \pm 0.20 \mathrm{~mm}$. The mean distance between medial and lateral epicondyle (BC) was $59.76 \pm 0.39 \mathrm{~mm}$ on the right side, $59.09 \pm 0.42$ $\mathrm{mm}$ on the left side and the mean of both $59.40 \pm 0.29$ $\mathrm{mm}$. Finally, the average distance between the distal edge of the olecranon fossa and the trochlea (CD) was $17.02 \pm 0.24 \mathrm{~mm}$ on the right side, $16.81 \pm 0.22 \mathrm{~mm}$ on the left side and the average of both of $16.90 \pm 0.16 \mathrm{~mm}$.

No differences were found between the right and left sides in all parameters analyzed $(\mathrm{p}>0.05)$.

\section{Discussion}

Knowledge of the bone morphology that integrates the elbow joint is essential to deal with significant dysfunctionsinthis region. The results of morphological studies of the distal epiphysis in different populations can help doctors, physiotherapists and orthopedists in the treatment of elbow lesions, especially intraarticular fractures. ${ }^{3,4}$ In addition, assistance in forensic, anthropometric and archaeological studies is highlighted due to the large evidence about the distal epiphysis of humerus indicating specific characteristics of a given population and its region..$^{8,10-12}$

In our qualitative analysis, we observedthat the most common type of olecranon fossa was type A, triangular (51.8\%). This result is corroborated with a study carried out in South Africa, where 608 adult humeri were evaluated and, among these, $69.08 \%$ were type A and $30.92 \%$ of type B. ${ }^{8}$ In contrast, studies carried out in dry Egyptian humeri and in Eskimo population showed different results with predominance of the type B (54.54\% and $63.63 \%$, respectively) $)^{9,11}$ (Table 3$)$.

The shape of the olecranon fossa is one of the nonmetric morphometric patterns that has a higher level of accuracy to determine the individual's gender. The difference in the prevalence of the shape of the olecranon fossa is mainly due to the unique characteristics of each region and the population studied. We have to take into account gender and the availability of corpses. ${ }^{11}$ Thus, it is possible to state that in the present study, possibly, the predominance of type A olecranon fossa was due toa greater number of male skeletons in our study. ${ }^{6}$

Regarding the morphometric analysis, we observed that there were no differences between the measurements of the right and left antimers in the humeri studied. In the literature, in a study carried out in South India it is observed that the average values of XY are higher than those of the present study (21.56 $\mathrm{mm}$ on the right side and $19.55 \mathrm{~mm}$ on the left side). ${ }^{13}$ The same is observed in Turkey and Mangalore populations. ${ }^{5,14}$ In contrast, the average $\mathrm{CD}$ values are lower on the right and left sides $(13.3$ and $14.2 \mathrm{~mm}$, respectively). ${ }^{13}$ The same $\mathrm{CD}$ variation also occurs in North India, while XY remains in line with our study. ${ }^{15}$

$A B$ value in North India has an overall mean very similar to that obtained in our study $(32.2 \mathrm{~mm}){ }^{15}$ In Egyptians, mean $\mathrm{BC}$ values are lower than those of the present study on the right and left sides (55.5 and $55.4 \mathrm{~mm}$ ) and have similar ZW values (25.03 on the right side and 25.3 on the left side). ${ }^{9}$ In addition, when data from various areas of India are analyzed, with no predominance of region, the afore mentioned measures $\mathrm{BC}$ and $\mathrm{ZW}$ both present lower values than our study (56.2 $\mathrm{mm}$ and $22.6 \mathrm{~mm}$ ), respectively. ${ }^{12}$

Table 3. Comparison of the percentages of olecranon types in different populations.

\begin{tabular}{l|c|c|c}
\multicolumn{1}{c|}{ Region } & Number of humerus & Type A (\%) & Type B (\%) \\
\hline Wanek et al, 2002 ${ }^{11}$, Portland & 44 & 36.4 & 63.6 \\
\hline Vance et al, $2011^{8}$, South Africans & 608 & 69.0 & 30.9 \\
\hline Hegazy et al, 2013', Egypt & 132 & 45.4 & 54.5 \\
\hline Present study, Brazil & 134 & 52.2 & 47.8 \\
\hline
\end{tabular}


The results of this study and others in the literature are directly dependent on factors such as age, sex, race, environmental factors and the material used for data collection..$^{8,9,11}$ Some studies, for example, used different equipment for data collection, such as osteometric plate, scale, Vernier Calliper compass, radiographs and measuring tape. ${ }^{9,12,13,15}$ This may explain some differences in the quantitative analysis. (Table 4).

The determination of sexual dimorphism was not analyzed in this study, since we need a prior knowledge of the genders studied to determine a good level of accuracy. The analysis of the shape of the olecranon fossa and two other non-metric parameters (medial epicondyle angle and trochlear extension) are the morphological features which could classify in male and female humeri. ${ }^{6}$ This could be done in future studies.

Finally, this morphometric analysis of the distal epiphysis of humerus unites information that can helpanthropometric recognition, sexual determination, external influence on bone formation and treatments for elbow joint disorders.

\section{Conclusion}

For the first time, an analysis of the morphometric parameters of the distal humerus epiphysis and the main bone structures that compose the elbow joint in the Northeast region of Brazil, perhaps in Brazil, was carried out. The predominance of the triangular shape of the olecranon fossa was described in this study and the quantitative measurements showed some differences in comparison to the literature. No differences between the right and left antimers were found.

The knowledge of the morphological patterns of the distal epiphysis in a specific population in Northeast region of Brazil might improve the work of several health professionals such as orthopedists, physiotherapists and radiologists. Diagnosis and treatment could have a better planning with this data, improving, for example, the creation of prostheses in articular fractures of the elbow joint. In addition, data can be useful for forensic, anthropometric and archaeological areas, revealing particular information of each population helping to identify and classify the sexual dimorphism and region of origin of the corpse.

Table 4. Comparison of distal epiphysis of humerus measurements in different populations.

\begin{tabular}{|c|c|c|c|c|c|}
\hline \multirow{2}{*}{ Population } & \multicolumn{5}{|c|}{ Measurements (mm) } \\
\hline & $\mathbf{X Y}$ & ZW & AB & BC & CD \\
\hline \multirow{3}{*}{ Hegazy et al, 2013, ${ }^{9}$ Egypt } & - & $\mathrm{R}: 25.03$ & - & R: 55.5 & - \\
\hline & & L: 25.38 & & L: 55.4 & \\
\hline & & T: $25.20 \pm 6.64$ & & T: 55.45 & \\
\hline \multirow{3}{*}{$\begin{array}{l}\text { Kantha et al, 2014,13 South } \\
\text { India }\end{array}$} & $\mathrm{R}: 21.56$ & - & $\mathrm{R}: 31.6$ & - & R: 14.0 \\
\hline & L: 19.55 & & L: 32.7 & & L: 14.4 \\
\hline & $\mathrm{T}: 20.55 \pm 2.42$ & & $\mathrm{~T}: 32.1 \pm 0.24$ & & $\mathrm{~T}: 14.2 \pm 0.13$ \\
\hline \multirow{3}{*}{ Ashiyanil et al, 2016,12 India } & - & $\mathrm{R}: 22.6$ & - & R: 56.6 & - \\
\hline & & L: 22.6 & & L: 55.8 & \\
\hline & & $\mathrm{T}: 22.6 \pm 0.18$ & & $\mathrm{~T}: 56.2 \pm 0.39$ & \\
\hline \multirow{3}{*}{$\begin{array}{l}\text { Naqshi et al, 2018, Jammu, } \\
\text { North Indian }\end{array}$} & R: 17.7 & - & R: 31.9 & - & R: 14.1 \\
\hline & L: 18.2 & & L: 32.6 & & L: 14.3 \\
\hline & $\mathrm{T}: 18.0 \pm 0.17$ & & $\mathrm{~T}: 32.2 \pm 0.27$ & & $\mathrm{~T}: 14.2 \pm 0.16$ \\
\hline \multirow{3}{*}{ Present Study } & R: 18.10 & R: 24.24 & R: 32.95 & R: 59.76 & R: 17.02 \\
\hline & L: 18.65 & $\mathrm{~L}: 24.73$ & L: 32.94 & L: 59.09 & L: 16.81 \\
\hline & $\mathrm{T}: 18.39 \pm 0.18$ & $\mathrm{~T}: 24.50 \pm 0.21$ & $\mathrm{~T}: 32.95 \pm 0.20$ & $\mathrm{~T}: 59.40 \pm 0.29$ & $\mathrm{~T}: 16.90 \pm 0.16$ \\
\hline
\end{tabular}

R: Right; L: Left; T: Total; XY: height of the olecranon fossa; ZW: width of the olecranon fossa; AB: distance between proximal edge of the olecranon fossa and the trochlea; $\mathrm{BC}$ : distance between medial and lateral epicondyle; CD: distance between the distal edge of the olecranon fossa and the trochlea. 


\section{References}

1. Moore KL, Dalley AF, Agur AMR. Anatomia Orientada para a Clínica. 7nd ed. Rio de Janeiro: Guanabara Koogan; 2014.

2. Tortora JG, Nielsen TM. Princípios de Anatomia Humana. 12nd ed. Rio de Janeiro: Guanabara Koogan; 2013.

3. Shaerf DA, Vanhegan IS, Dattani R. Diagnosis, management and complications of distal humerus lateral condyle fractures in children. Shoulder Elbow 2018;10(2)114-120.

4. Bégué T. Articular fractures of the distal humerus. Orthop Traumatol Surg Res 2014; 100(1 Suppl):S55-63.

5. Akman, SD, Karakas P, Bozkir MG. The morphometric measurements of humerus segments. Turk J Med Sci 2006;36(2):81-85.

6. Rogers TL. A visual method of determining the sex of skeletal remains using the distal humerus. J Forensic Sci 1999;44(1):57-60.

7. Vance VL, Steyn M. Geometric morphometric assessment of sexually dimorphic characteristics of the distal humerus. HOMO 2013;64(5):329-340.

8. Vance VL, Steyn M, L'abbé EN. Nonmetric Sex Determination from the Distal and Posterior Humerus in Black White South Africans. J Forensic Sci 2011;56(3):710-714.

9. Hegazy AA. Radiographic morphometric study of the normal distal humerus in adult Egyptians. Int J Adv Res 2013;1(9):155-161.

10. Muñoz Jl, Liñares-Iglesias $M$, Suárez-Peñaranda JM, Mayo M, Miguéns X, Rodríguez-Calvo MS, et al. Stature estimation from radiographically determined long bone length in a Spanish population sample. J Forensic Sci 2001;46(2):363-366.

11. Wanek VL. A qualitative analysis for sex determination in humans utilizing posterior and medial aspects of the distal humerus. Dissertations and Theses 2002; paper 3571.

12. Ashiyanil ZA, Solankil S, Mehta CD. The morphometric measurement of segments of humerus. J Res Med Den Sci 2016;4(1):38-40.

13. Kantha BML, Kulkarni R. Estimation of total length of humerus from its fragments in South Indian Population. Int J Anat Res 2014:2(1):213-220.

14. Somesh MS, Prabhu, LV, Shilpa K, Pai MM, Krishnamurthy A, Murlimanju BV. Morphometric study of the humerus segments in Indian Population. Int J Morphol 2011;29(4):1174-1180.

15. Naqhi BF, Shah AB, Gupta S. Olecranon fossa in humeri of North Indian Population of Jammu- A Morphometric Study. J Med Sci Clin Res 2018;6(2):250-253.
Received: Abril 6, 2020

Accepted: January 14, 2021
Corresponding author

André de Sá Braga Oliveira

E-mail: andre.sboliveira@gmail.com 